\title{
Amino Acids Glycation Section
}

\author{
Naila Rabbani $\cdot$ Paul J. Thornalley
}

Published online: 9 July 2011

(C) Springer-Verlag 2011

It is a great pleasure and honour to present the following reviews on glycation research to kick-off the new Glycation Section of Amino Acids. We start with an introduction to glycation, describing in brief the history of glycation research and its current standing in research across the scientific disciplines (Rabbani and Thornalley 2010a). There are then reviews on current issues of glycation in food science: 'Physiological relevance of dietary melanoidins' by Morales et al. (2010), 'Glycation products in infant formulas - chemical, analytical, and physiological aspects' by Pischetsrieder and Henle (2010) and 'Health effects of dietary Maillard reaction products-The results of ICARE and other studies' by Tessier and BirlouezAragon (2010). New types of glycation of current multidisciplinary interest are reviewed: 'Methylglyoxal, glyoxalase 1 and the dicarbonyl proteome' Rabbani and Thornalley (2010b), 'Enzymatic repair of early glycation' by Van Schaftingen et al. (2010), and 'Advanced Glycation Endproducts: From Precursors to the Receptor RAGE' by Ramasamy et al. (2010). There are then reviews on the current focus of glycation in biomedical research. Four reviews focus on the important impact of glycation in diabetes and related complications: 'Lipid glycation modifications in diabetes and atherosclerosis' by Miyazawa et al. (2010), 'Glycation and biomarkers of vascular complications of diabetes' by Beisswenger (2010), 'Glycation

\footnotetext{
N. Rabbani $(\bowtie) \cdot$ P. J. Thornalley

Clinical Sciences Research Institute, Warwick Medical School, University of Warwick, University Hospital, Clifford Bridge

Road, Coventry CV2 2DX, UK

e-mail: N.Rabbani@warwick.ac.uk

P. J. Thornalley

e-mail: P.J.Thornaley@warwick.ac.uk
}

in diabetic nephropathy' by Forbes and Cooper (2010), and 'Early- and advanced non-enzymatic glycation in diabetic vascular complications and search for therapeutics' by Schalkwijk and Miyata (2010). Finally, the compilation concludes with two reviews on the biomedical importance of glycation in ageing-related disorders: 'The Pathogenic Role of the Maillard Reaction in the Aging Eye' by Nagaraj et al. (2010), and 'Advanced glycation endproducts and their pathogenic roles in neurological disorders' by Münch et al. (2010). We thank all authors for their commitment and contributions to this compilation and we trust that this will be the start of an expanding and long-standing partnership of Amino Acids with glycation research.

\section{References}

Beisswenger PJ (2010) Glycation and biomarkers of vascular complications of diabetes. Amino Acids (in this issue). doi: 10.1007/s00726-010-0784-z

Forbes JM, Cooper ME (2010) Glycation in diabetic nephropathy. Amino Acids (in this issue). doi:10.1007/s00726-010-0771-4

Miyazawa T, Nakagawa K, Shimasaki S, Nagai R (2010) Lipid glycation and protein glycation in diabetes and atherosclerosis. Amino Acids (in this issue). doi:10.1007/s00726-010-0772-3

Morales FJ, Somoza V, Fogliano V (2010) Physiological relevance of dietary melanoidins. Amino Acids (in this issue). doi:10.1007/ s00726-010-0774-1

Münch G, Westcott B, Menini T, Gugliucci A (2010) Advanced glycation endproducts and their pathogenic roles in neurological disorders. Amino Acids (in this issue). doi:10.1007/s00726010-0777-y

Nagaraj RH, Linetsky M, Stitt AW (2010) The Pathogenic role of Maillard reaction in the aging eye. Amino Acids (in this issue). doi:10.1007/s00726-010-0778-x

Pischetsrieder M, Henle T (2010) Glycation products in infant formulas: chemical, analytical, and physiological aspects. Amino Acids (in this issue). doi:10.1007/s00726-010-0775-0 
Rabbani N, Thornalley PJ (2010a) Glycation research in amino acids: a place to call home. Amino Acids (in this issue). doi:10.1007/ s00726-010-0782-1

Rabbani N, Thornalley PJ (2010b) Methylglyoxal, glyoxalase 1 and the dicarbonyl proteome. Amino Acids (in this issue). doi: 10.1007/s00726-010-0783-0

Ramasamy R, Yan SF, Schmidt AM (2010) Advanced glycation endproducts: from precursors to RAGE: round and round we go. Amino Acids (in this issue). doi:10.1007/s00726-010-0773-2

Schalkwijk CG, Miyata T (2010) Early- and advanced non-enzymatic glycation in diabetic vascular complications: the search for therapeutics. Amino Acids (in this issue). doi:10.1007/s00726010-0779-9

Tessier FJ, Birlouez-Aragon I (2010) Health effects of dietary Maillard reaction products: the results of ICARE and other studies. Amino Acids (in this issue). doi:10.1007/s00726010-0776-Z

Van Schaftingen E, Collard F, Wiame E, Veiga-da-Cunha M (2010) Enzymatic repair of Amadori products. Amino Acids (in this issue). doi:10.1007/s00726-010-0780-3 